\title{
THEORETICAL AND EXPERIMENTAL STUDY ON STRESS-DEPENDENCY OF OIL-WATER RELATIVE PERMEABILITY IN FRACTAL POROUS MEDIA
}

\author{
GANG LEI, ${ }^{, \S}$ SHAOYUAN MO, ${ }^{\dagger}$ ZHENZHEN DONG, ${ }^{\ddagger}$ \\ CAI WANG* and WEIRONG LI* \\ ${ }^{*} E R E$ \& $B I C-E S A T$ \\ College of Engineering, Peking University \\ Beijing 100871, P. R. China \\ ${ }^{\dagger}$ Research Institute of Petroleum Exploration 83 Development \\ PetroChina, Beijing 100083, P. R. China \\ ${ }^{\ddagger} X i$ 'an Shiyou University, Xi'an 710065, P. R. China \\ §lg1987cup@126.com
}

Received September 26, 2017

Accepted November 27, 2017

Published March 9, 2018

\begin{abstract}
The coupled flow deformation behavior in the porous media has drawn tremendous attention in various scientific and engineering fields. It is reported that the porous media will be compressed and relative permeability in porous media will be changed as the effective stress increases. However, previous studies provided contradictory evidence for the stress-dependent irreducible water saturation and stress-dependent relative permeability. Until now, appropriate stress-dependent relative permeability curve for two-phase flow through porous media remains unclear. The goal of this work was to theoretically and experimentally study the stress-dependent relative permeability. Laboratory sample flooding tests were conducted to measure two-phase
\end{abstract}

\footnotetext{
${ }^{\S}$ Corresponding author.
}

This is an Open Access article published by World Scientific Publishing Company. It is distributed under the terms of the Creative Commons Attribution 4.0 (CC-BY) License. Further distribution of this work is permitted, provided the original work is properly cited. 
relative permeability in porous media under changing effective stress, and a corresponding theoretical model of stress-dependent relative permeability was derived to interpret the experimental results. The predictions from the proposed analytical model exhibited similar variation trends as the experimental data, which verified the theoretical model. Though the results for the stress-dependent relative permeability from previous studies are different, or even opposite, our proposed model with different conditions can provide explanations to these different results. This work provides a comprehensive experimental and theoretical study of stress-dependent relative permeability in porous media, which is beneficial to accurate performance forecasts for the coupled flow deformation behavior in porous media.

Keywords: Stress-Dependent Relative Permeability; Experimental Investigation; Theoretical Model; Effective Stress; Drawdown Pressure.

\section{NOMENCLATURE}

Latin symbols

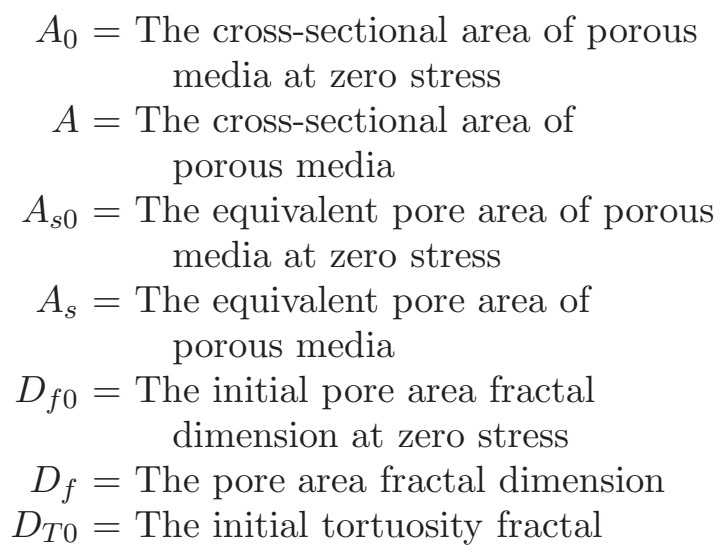
dimension at zero stress

$D_{T}=$ The tortuosity fractal dimension

$E=$ Rock elastic modulus of porous media

$f=$ The probability density function for pore size distribution

$I=$ Rock wetting index

$K=$ The absolute permeability of porous media under effective stress

$K_{r}=$ The relative permeability of porous media under effective stress

$L_{\tau}=$ Actual length of a tortuous capillary

$L_{0}=$ The initial representative length of a capillary at zero stress

$L=$ The representative length of a capillary under effective stress

$N=$ The number of pores of a unit cell

$p=$ The pressure

$\Delta p=$ The drawdown pressure

$p_{\text {eff }}=$ The effective stress

$R=$ The particle radius

$r_{0}=$ The initial equivalent pore radius of capillary at zero stress

$r=$ The equivalent pore radius of capillary under effective stress
$S_{w}=$ Water saturation

$S_{b}=$ The boundary layer fluid saturation

$S_{\mathrm{wc}}=$ The irreducible water saturation

$S_{\text {or }}=$ The residual oil saturation

Greek symbols

$$
\begin{aligned}
\bar{\tau} & =\text { The average tortuosity } \\
\mu & =\text { Fluid viscosity } \\
\varphi_{0} & =\text { The porosity of porous } \\
& \text { media before deforming } \\
\varphi & =\text { The porosity under effective stress } \\
\nu & =\text { The poisson's ratio } \\
\delta & =\text { The boundary layer thickness }
\end{aligned}
$$

Subscripts

$$
\begin{aligned}
\text { av } & =\text { Average } \\
\text { eff } & =\text { Effective } \\
\max & =\text { Maximum values } \\
\max 0 & =\text { Initial maximum values } \\
& \quad \text { at zero stress } \\
\min & =\text { Minimum values } \\
\min 0 & =\text { Initial minimum values } \\
& \quad \text { at zero stress } \\
\text { nw }= & \text { Nonwetting phase } \\
w & =\text { Wetting phase } \\
\tau & =\text { Tortuosity } \\
0= & \text { Initial state. }
\end{aligned}
$$

\section{INTRODUCTION}

The fluid transport through porous media affected by stress has drawn tremendous attention in various scientific and engineering fields, including hydraulics, $\frac{112}{12}$ physics,,$\frac{34}{\sqrt{4}}$ chemistry,$[5]$ petroleum engineering, ${ }^{6-12}$ etc. It is reported that the porous media will be compressed as the effective stress increases, causing fluid flow behavior in porous media to be strongly stress-dependent 1214 Therefore, it is essential to understand and quantify the 
stress-dependent relative permeability to characterize the multiphase fluid flow behaviors. However, the reported studies for the effects of changing stress on relative permeability are very scarce and the stress sensitivity of relative permeability has received little attention. $15-20$ The relevant studies together with their conditions and results are summarized in Table 1 . These studies provide contradictory evidence for the stress-dependent relative permeability ${ }^{[25}$ For instance, McDonald et al $!^{[22}$ suggested that the large effective stress reduced the irreducible water saturation. However, to the contrary, the results from others $1423 \mid 24$ clearly showed that the higher irreducible water saturation corresponded to increasing stress. Recently, Huo and Benson $^{25}$ conducted a series of experiments of nitrogen-water relative permeability in a fracture under various stresses and concluded that higher stress might lower the irreducible water saturation under the same flow rate.

Through the discussions above, we concluded that the characteristic behaviors of stressdependent relative permeability were still not well determined. And appropriate stress-dependent relative permeability curve to two-phase flow through porous media remains unclear. The specific objectives of this work are as follows:

(1) to conduct laboratory experiments to measure stress-dependency of relative permeability in porous media under changing pressure conditions (effective stress and drawdown pressure);

(2) to establish a more reasonable quantitative model to interpret the experimental results;

(3) to verify the model via the experimental data and investigate the effects of the relevant parameters on stress-dependent relative permeability.

\section{EXPERIMENTAL WORKS}

\subsection{Apparatus}

The schematic of apparatus for stress-dependent relative permeability is shown in Fig. 1. A high pressure injection pump equipped with two high pressure containers is used to provide the driving

Table 1 A List of Some Studies for Stress-Dependent Permeability Curves.

\begin{tabular}{|c|c|c|c|}
\hline Author & Year & Conditions and Methods & Conclusions \\
\hline Pyrak-Nolte et al.,, 21 & 1990 & $\begin{array}{l}\text { A simulation work for a rough fracture } \\
\text { with a uniform reduction in aperture }\end{array}$ & $\begin{array}{l}\text { Nonwetting phase relative permeability tends } \\
\text { to have a larger reduction than the wetting } \\
\text { phase during the close of fracture aperture }\end{array}$ \\
\hline McDonald et al. $\stackrel{22}{22}$ & 1991 & $\begin{array}{l}\text { Oil-water drainage tests for Edwards } \\
\text { limestone natural fracture }\end{array}$ & $\begin{array}{l}\text { (1) Increasing effective stress results in reduc- } \\
\text { ing the residual water saturation } \\
\text { (2) The relative permeability curve shifts to } \\
\text { left with the increased effective stress }\end{array}$ \\
\hline Lian et al.,, 23 & 2012 & $\begin{array}{l}\text { Oil-water imbibition tests under the same } \\
\text { pressure drop for naturally fractured car- } \\
\text { bonate rocks }\end{array}$ & $\begin{array}{l}\text { (1) The irreducible water saturation increases } \\
\text { with increasing stress, while the residual oil } \\
\text { saturation remains the same } \\
\text { (2) A lower end-point water relative perme- } \\
\text { ability at higher stress }\end{array}$ \\
\hline Zheng et al., 24 & 2013 & $\begin{array}{l}\text { Gas-water relative permeability change } \\
\text { trend at different confining pressure is } \\
\text { studied with laboratory experiments }\end{array}$ & $\begin{array}{l}\text { (1) The increasing stress leads to overall drop } \\
\text { of gas/water relative permeability } \\
\text { (2) The irreducible water saturation increases } \\
\text { with increasing stress }\end{array}$ \\
\hline Lei et al., 14 & 2015 & $\begin{array}{l}\text { A fractal model to stress-dependency of } \\
\text { relative permeability for tight sandstone }\end{array}$ & $\begin{array}{l}\text { (1) The irreducible water saturation increases } \\
\text { with increasing stress } \\
\text { (2) The relative permeability ratio } K_{\mathrm{rw}} / K_{\mathrm{rg}} \\
\text { decreases with increasing stress }\end{array}$ \\
\hline Huo and Bensor 25 & 2016 & $\begin{array}{l}\text { Laboratory core flooding tests were } \\
\text { applied to measure the nitrogen-water rel- } \\
\text { ative permeability in a fracture under var- } \\
\text { ious stress }\end{array}$ & $\begin{array}{l}\text { (1) Under constant pressure drops, the } \\
\text { irreducible water saturation increases with } \\
\text { increasing stress } \\
\text { (2) Under same flow rates, higher confining } \\
\text { stress decreases the irreducible water satura- } \\
\text { tion }\end{array}$ \\
\hline
\end{tabular}




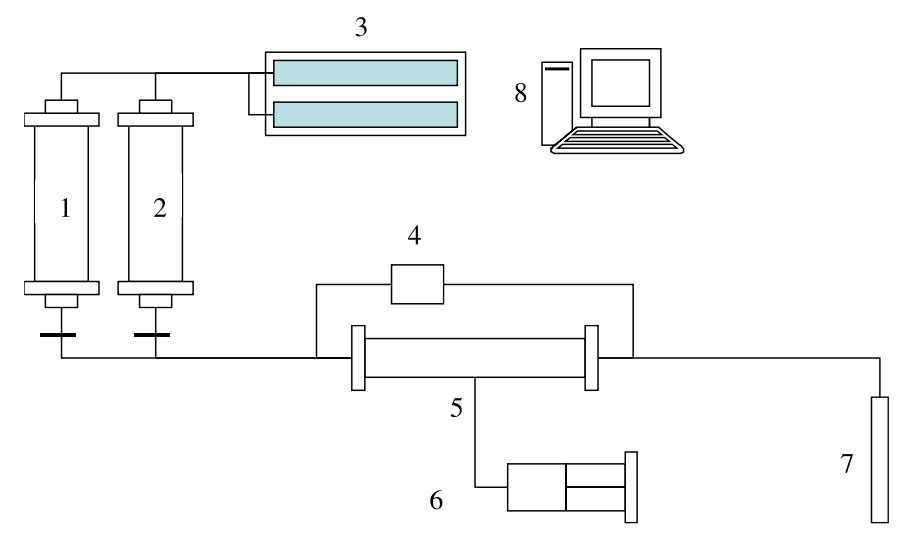

1-Source oil; 2-Source water; 3-Quizix pump; 4-Pressure sensor; 5-Core holder; 6-Confining pressure pump; 7-Measuring cylinder; 8-Data capture system

Fig. 1 Schematic of apparatus of the core sample flooding experiment.

pressure. The pumping flow could be recorded from $0.01 \mu \mathrm{L} / \mathrm{min}$ to $50 \mathrm{~mL} / \mathrm{min}$ and the display accuracy of pumping rate is $0.01 \mu \mathrm{L} / \mathrm{min}$. The working pressure of the pump ranges from $0.068 \mathrm{MPa}$ to $68 \mathrm{MPa}$ and the display accuracy of pressure is $6.895 \mathrm{kPa}$. A cylindrical core holder is used to fix the core sample and a hand pump equipped with the core holder is used to provide the radius confining pressure. A differential pressure transducer with the accuracy of 1 psi is used to record the pressure drop between the inlet and outlet.

\subsection{Samples and Fluids}

The experimental parameters of the samples are summarized in Table 2, Rocks are outcrops collected from Ordos Basin. To lower the impact of heterogeneity and obtain cores with similar characteristics, samples in the same group were parallelly drilled from the same rock. Thus, the pores of samples could be thought to be structurally the same. The experimental fluids were simulated formation water with a viscosity of $0.676 \mathrm{mPa} \cdot \mathrm{s}$ and sample oil with a viscosity of $2.662 \mathrm{mPa} \cdot \mathrm{s}$, respectively.

\subsection{Procedures}

The laboratory tests for stress-dependent oilwater relative permeability were conducted using unsteady-state method, 26 and the primary experimental procedure mainly includes four steps:

(1) Weigh the cleaned and dried samples, and saturate them with simulated formation water. Then, weigh the saturated samples again to calculate the porosity.

(2) Place a saturated sample into the core holder, displace the simulated formation water out of the core sample using the oil until no water

Table 2 Parameters Used in the Experiments.

\begin{tabular}{|c|c|c|c|c|c|c|c|c|c|}
\hline $\begin{array}{c}\text { Experiment } \\
\text { Number }\end{array}$ & Sample & $\begin{array}{l}\text { Length } \\
(\mathrm{cm})\end{array}$ & $\begin{array}{c}\text { Diameter } \\
(\mathrm{cm})\end{array}$ & $\begin{array}{l}\text { Initial } \\
\text { Porosity } \\
\quad(\%)\end{array}$ & $\begin{array}{c}\text { Initial } \\
\text { Permeability } \\
\left(10^{-3} \mu \mathrm{m}^{2}\right)\end{array}$ & $\begin{array}{c}\text { Rock Elastic } \\
\text { Modulus } \\
(\text { GPa })\end{array}$ & $\begin{array}{c}\text { Poisson's } \\
\text { Ratio }\end{array}$ & $\begin{array}{c}\text { Drawdown } \\
\text { Pressure } \\
(\mathrm{MPa})\end{array}$ & $\begin{array}{l}\text { Effective } \\
\text { Stress } \\
\text { (MPa) }\end{array}$ \\
\hline \multirow[t]{2}{*}{1} & $\mathrm{~N}-2 \mathrm{H}$ & 5.54 & 2.55 & 7.82 & 2.49 & 32.8 & 0.21 & 5 & 20 \\
\hline & $\mathrm{N}-3 \mathrm{H}$ & 4.25 & 2.55 & 8.01 & 2.51 & 32.8 & 0.21 & 5 & 40 \\
\hline \multirow[t]{3}{*}{2} & N-Y7 & 5.81 & 2.54 & 15.86 & 4.08 & 12.6 & 0.25 & 3 & 3 \\
\hline & N-Y3 & 6.35 & 2.54 & 14.88 & 3.89 & 12.6 & 0.25 & 3 & 17 \\
\hline & N-Y4 & 6.26 & 2.54 & 15.66 & 4.00 & 12.6 & 0.25 & 3 & 12 \\
\hline \multirow[t]{4}{*}{3} & $\mathrm{Y}-1 \mathrm{~N}$ & 3.68 & 2.48 & 11.57 & 9.78 & 25.5 & 0.24 & 2 & 20 \\
\hline & $\mathrm{Y}-2 \mathrm{~N}$ & 3.16 & 2.48 & 11.35 & 9.58 & 25.5 & 0.24 & 3 & 20 \\
\hline & $\mathrm{Y}-3 \mathrm{~N}$ & 3.16 & 2.48 & 11.26 & 9.66 & 25.5 & 0.24 & 4 & 20 \\
\hline & $\mathrm{Y}-4 \mathrm{~N}$ & 3.16 & 2.48 & 11.14 & 9.73 & 25.5 & 0.24 & 5 & 20 \\
\hline
\end{tabular}




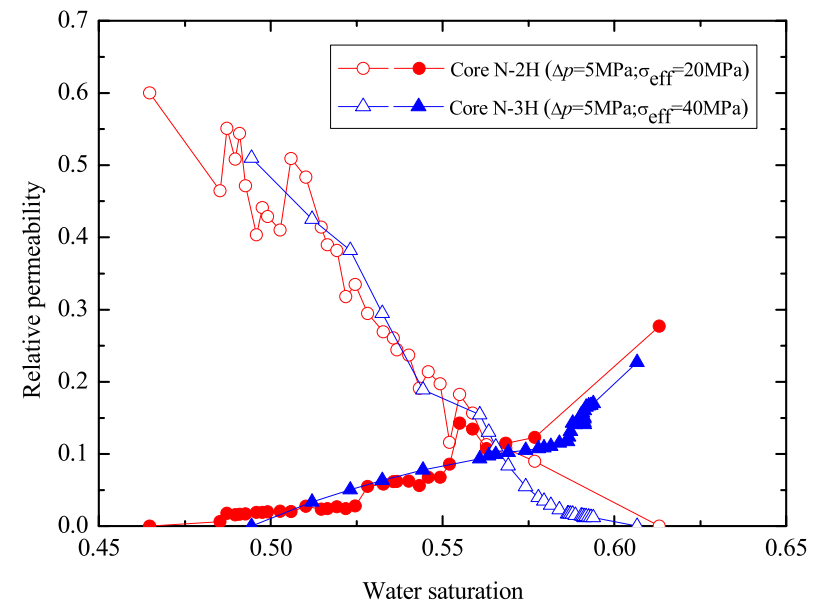

Fig. 2 Relative permeability of samples (sample N-2H and sample N-3H) under the different effective stress and the constant drawdown pressure of $5 \mathrm{MPa}$.

flows out and the flow rate at the outlet end is stable. Then, calculate the absolute permeability.

(3) Displace oil with the water sample under a constant pressure condition (a constant confining stress and a constant drawdown pressure level). Record the drawdown pressure, the water phase production and oil phase production until the sample reaches the residual water state.

(4) Calculate the relative permeability based on JBN method $[27$ Then, conduct another experiment with a new sample under a different pressure condition.

Three series of experiments were carried out to study the stress-dependent oil-water relative permeability. In the same set of experiments, the

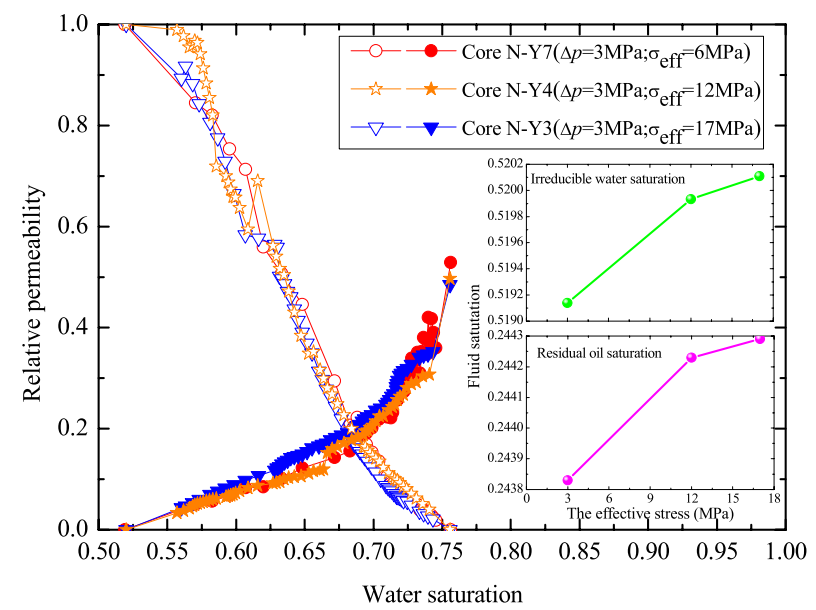

Fig. 3 Relative permeability of samples (sample N-Y7, sample N-Y4 and sample N-Y3) under the different effective stress and the constant drawdown pressure of $3 \mathrm{MPa}$.

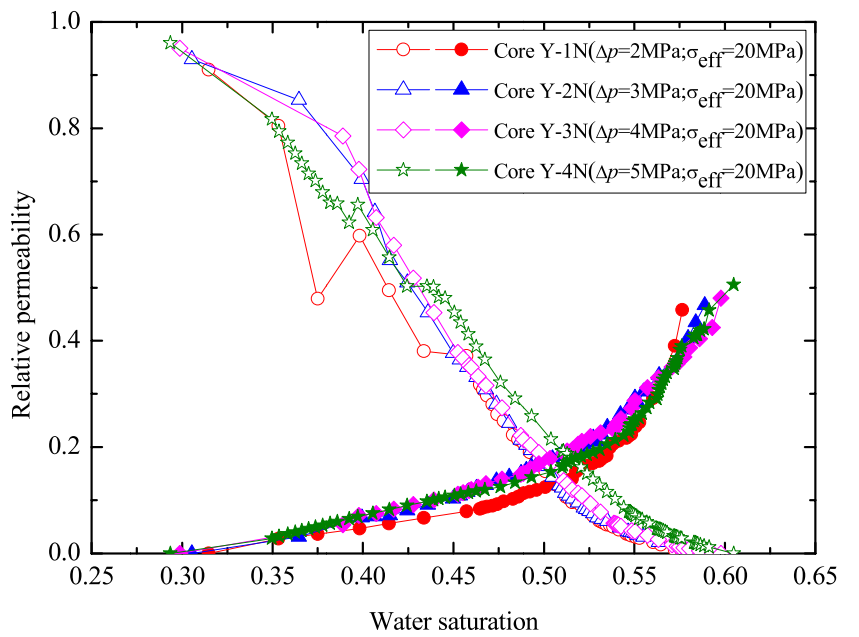

Fig. 4 Relative permeability of samples (sample $\mathrm{Y}-1 \mathrm{~N}$, sample $\mathrm{Y}-2 \mathrm{~N}$, sample $\mathrm{Y}-3 \mathrm{~N}$ and sample $\mathrm{Y}-4 \mathrm{~N}$ ) under the different drawdown pressure and the constant effective stress of $20 \mathrm{MPa}$.

cylindrical samples, extracted from the same region, had the same structure properties. The stressdependent relative permeability curves are illustrated in Figs. 2 through 4. As can be seen, the oil-water relative permeability curves change with the effective stress and the drawdown pressure. Figures 2 and 3 demonstrate the relationships of relative permeability versus water saturation for the different effective stress and the constant drawdown pressure. Figures 2 and 3 show that the irreducible water saturation and residual oil saturation increase with effective stress. Figure 4 illustrates relative permeability versus water saturation for the different drawdown pressure and the constant effective stress. As shown in Fig. 4, the irreducible water saturation and residual oil saturation decrease as drawdown pressure increases, which is in good agreement with the experimental data!28

\section{THEORETICAL MODEL}

As stated in many documents, the interspaces in real porous media have fractal characteristics. 29 Therefore, it is certain that the fractal feature is present in the pore size distribution of porous media. ${ }^{35+39}$ It was assumed that the porous media was composed of a bundle of capillary bundles and a single capillary with the equivalent radius $r$ was made up of a packing of three equivalent spherical grains $[40]$ The change of pore-throat size could be determined by the deformation of the equivalent spherical grains ${ }^{13 / 40}$ (Fig. 5).

For a single capillary with equivalent radius $r_{0}$ before deformation (Fig. 5a), the equivalent pore 


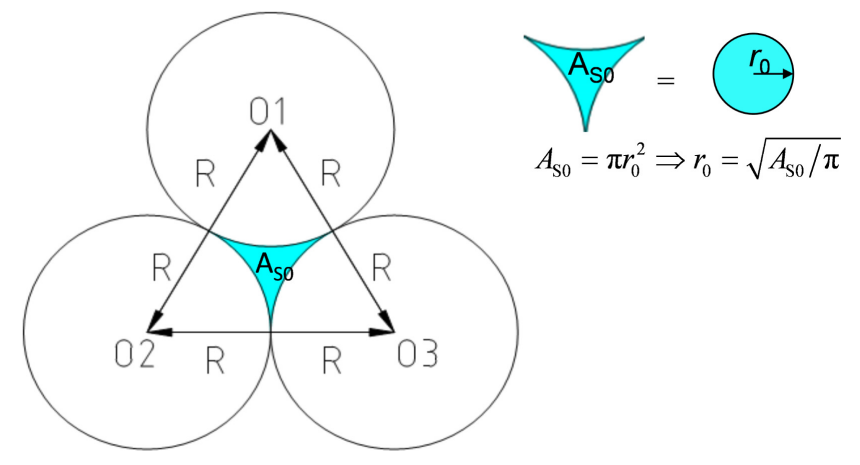

(a) Before deformation

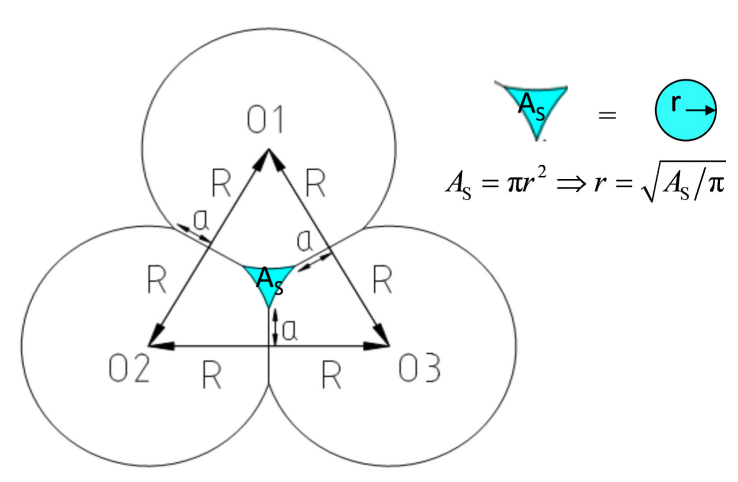

(b) After deformation

Fig. 5 Mechanical schematic diagram of single capillary.

radius after deforming (Fig. 5b) can be obtained as 641

$$
r=r_{0}\left\{1-4\left[\frac{3 \pi\left(1-v^{2}\right) p_{\mathrm{eff}}}{4 E}\right]^{2 / 3}\right\},
$$

in which $r_{0}$ is the initial equivalent pore radius of capillary at zero stress, $p_{\text {eff }}$ is effective stress, $E$ is rock elastic modulus and $v$ is rock Poisson's ratio.

Based on the deformation equation of equivalent pore radius from Eq. (1) and fractal geometry theory, the pore structure characteristic parameters of porous media under stress can be expressed in Appendix A. With the pore structure characteristic parameters described in Appendix A and the absolute permeability model of the porous media at zero effective stress, $\stackrel{38}{,}$ the stress-dependent permeability can be written by extended Darcy's law $\frac{36}{36}$

$$
K=\frac{\pi D_{f} r_{\max }^{D_{f}-1-D_{T}} \int_{r_{\min }}^{r_{\max }}(r-\delta)^{4} r^{D_{T}-D_{f}-2} d r}{2^{4-D_{T}}\left(\frac{\pi D_{f}(1-\varphi)}{\varphi\left(2-D_{f}\right)}\right)^{\frac{D_{T}+1}{2}}},
$$

where $K$ is the absolute permeability of porous media under effective stress, $D_{f}$ is the pore area fractal dimension, $D_{T}$ is the tortuosity fractal dimension, $\varphi$ is the porosity under effective stress, $r_{\max }$ and $r_{\min }$ are the maximum and minimum equivalent pore radius, respectively. $\delta$ is the thickness of the immobile fluid (boundary layer fluid) film, which can be calculated by 38142

$$
\delta=a \cdot r \cdot e^{-b r} \cdot(\Delta p)^{-c} \cdot \mu_{\mathrm{av}},
$$

where $\mu_{\mathrm{av}}$ is the average viscosity of the boundary layer fluid. $a, b$ and $c$ are constant, which can be determined by the experimental data. Equation (3) indicates that the thickness of the immobile fluid film $\delta$ is a function of the equivalent pore radius and the drawdown pressure as well as the average viscosity of the fluid mixtures at boundary layer. Since the increasing effective stress lowers the equivalent pore radius, the thickness of the immobile fluid film $\delta$ will be affected by effective stress.

During two-phase flow in the capillary, the boundary layer fluid near the wall exists in the capillary in the form of liquid film, which cannot move. And the mobile fluid flow occurs in-between the boundary layer fluid. The boundary layer saturation is also known as the immobile phase saturation which can be written a $\$ 38143$

$$
S_{b}=1-\frac{\int_{r_{\min }}^{r_{\max }}(r-\delta)^{2} r^{-D_{T}-D_{f}} d r}{\int_{r_{\min }}^{r_{\max }} r^{2-D_{T}-D_{f}} d r} .
$$

The residual nonwetting fluid saturation and irreducible wetting fluid saturation in porous media are governed by 42

$$
\begin{aligned}
S_{\mathrm{wc}} & =\frac{1+I}{2} S_{b} \\
& =\frac{1+I}{2}\left[1-\frac{\int_{r_{\min }}^{r_{\max }}(r-\delta)^{2} r^{-D_{T}-D_{f}} d r}{\int_{r_{\min }}^{r_{\max }} r^{2-D_{T}-D_{f}} d r}\right], \\
S_{\mathrm{or}} & =\frac{1-I}{2} S_{b} \\
& =\frac{1-I}{2}\left[1-\frac{\int_{r_{\min }}^{r_{\max }}(r-\delta)^{2} r^{-D_{T}-D_{f}} d r}{\int_{r_{\min }}^{r_{\max }} r^{2-D_{T}-D_{f}} d r}\right],
\end{aligned}
$$

where $I$ is the rock wettability index, $S_{\mathrm{wc}}$ is the irreducible wetting fluid saturation and $S_{\text {or }}$ is the residual nonwetting fluid saturation. The relative permeability for each phase can be, respectively, 
expressed as

$$
\begin{aligned}
& K_{\mathrm{rw}}= \begin{array}{c}
\left(S_{\mathrm{w}}-S_{\mathrm{wc}}\right) \int_{r_{\min }}^{r_{\max }} r^{D_{T}-D_{f}-2} \\
\times\left[(r-\delta)^{2}-r^{2}\left(1-S_{w}\right)\right]^{2} d r
\end{array} \\
& \int_{r_{\min }}^{r_{\max }}(r-\delta)^{4} r^{D_{T}-D_{f}-2} d r \frac{S_{\mathrm{nw}}^{3} \int_{r_{\min }}^{r_{\max }} r^{D_{T}-D_{f}+2} d r}{\int_{r_{\min }}^{r_{\max }}(r-\delta)^{4} r^{D_{T}-D_{f}-2} d r} \\
&+\frac{2 \mu_{\mathrm{nw}}}{\mu_{w}} \frac{\times r^{D_{T}-D_{f}} d r}{\int_{r_{\min }}^{r_{\max }}(r-\delta)^{4} r^{D_{T}-D_{f}-2} d r}
\end{aligned}
$$

It can be found from Eq. (7) that the wetting phase stress-dependent relative permeability $k_{\mathrm{rw}}$ is a function of wetting phase fluid saturation, rock wettability index, effective stress and the boundary layer thickness as well as pore microstructure parameters. However, Eq. (8) reveals that the nonwetting phase stress-dependent relative permeability is not only the function of fluid saturation, boundary layer thickness, rock wettability index, effective stress and pore structure parameters but also related to the fluid viscosity ratio. More details about the relative permeability for each phase can be found in the work $\underline{43}$

According to the proposed model, the algorithm for determination of stress-dependent oil--water relative permeability can be summarized as follows:

(1) Select an initial permeability $K_{0}$ and initial porosity $\varphi_{0}$ of the porous media. Determine

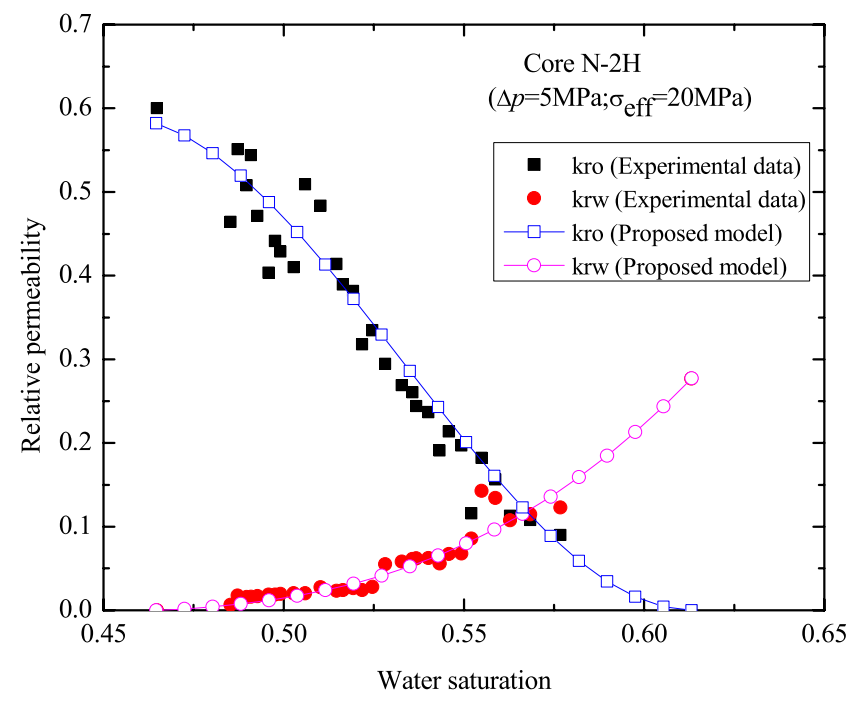

(a) $r_{\max 0}$ and $r_{\min 0}$ from Eq. (2). The constant parameters $E, v, \mu_{w}$ and $\mu_{\mathrm{nw}}$ are also given in this step $\left(E=32.8 \mathrm{GPa}, v=0.21 ; \mu_{w}=\right.$ $0.676 \mathrm{mPa} \cdot \mathrm{s}$ and $\mu_{\mathrm{nw}}=2.662 \mathrm{mPa} \cdot \mathrm{s}$ are used in this work). Determine pore fractal dimension $D_{f 0}$ from Eq. (A.4) and torturously fractal dimension $D_{T 0}$ from Eq. (A.6).

(2) Select the values of parameters $(a, b, c$ and $\Delta p)$, find $\delta$ from Eq. (3).

(3) Select the values of effective stress, find the stress-dependent pore radius $r$ from Eq. (1). Determine stress-dependent pore fractal dimension $D_{f}$ from Eq. (A.4) and stressdependent torturously fractal dimension $D_{T}$ from Eq. (A.6).

(4) Find fluid saturation and the relative permeability from Eqs. (4)-(8).

\section{RESULTS AND DISCUSSIONS}

This section aims at studying the novel analytical model in detail. In the following, we will first validate the proposed model by comparing the predicted and the experimental results. Then, the effect of the pressure condition (effective stress and drawdown pressure) on the irreducible water saturation will be investigated. Finally, the effect of the rock wettability index, pore structural parameters of porous media and fluid viscosity ratio on the stress-dependency of relative permeability will be discussed in detail.

Figures 68 demonstrate the predictions of relative permeability curves by the proposed model

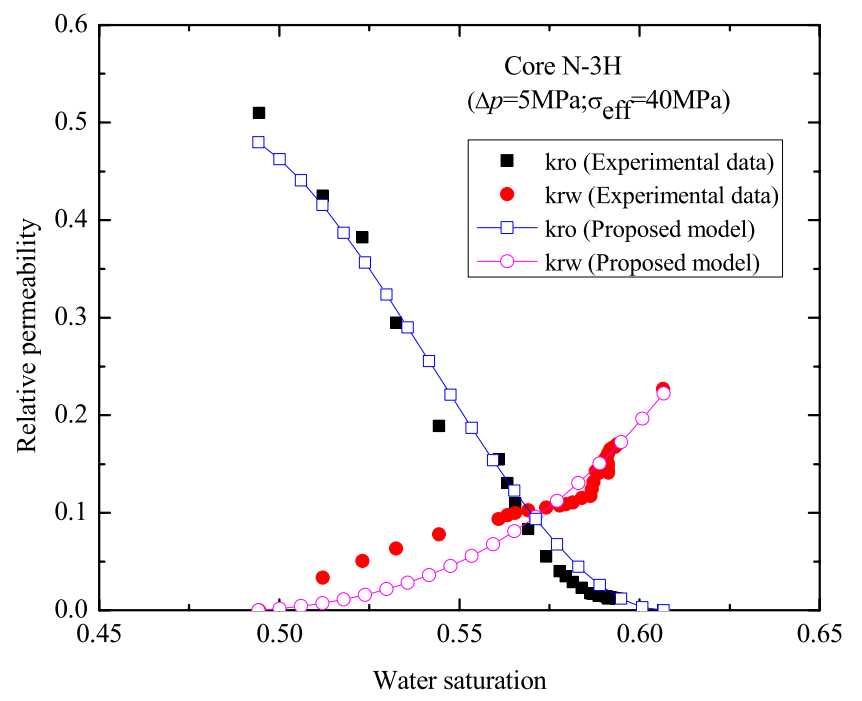

(b)

Fig. 6 Comparison between the experimental and predicted relative permeability curves for sample N-2H and sample N-3H. 


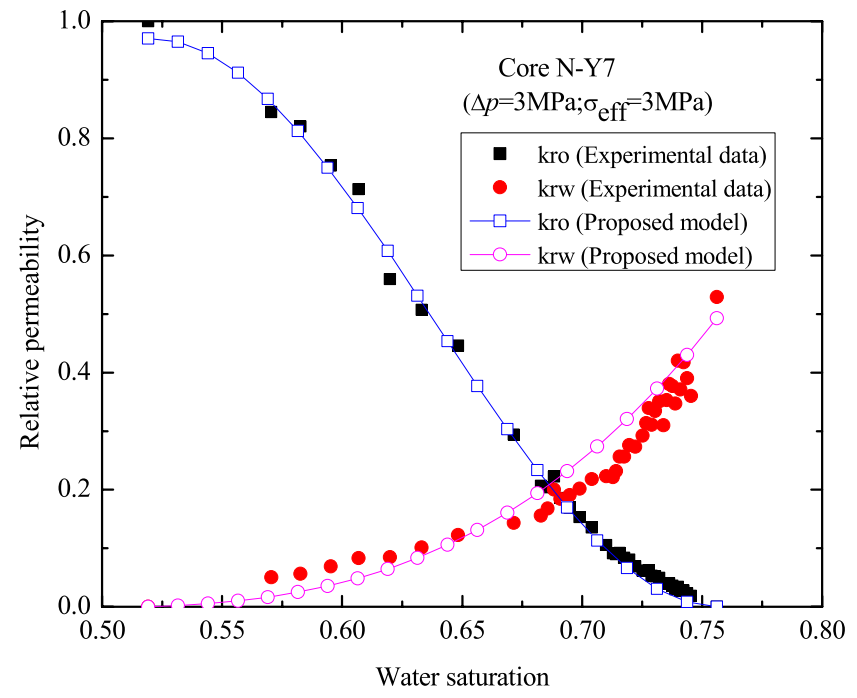

(a)

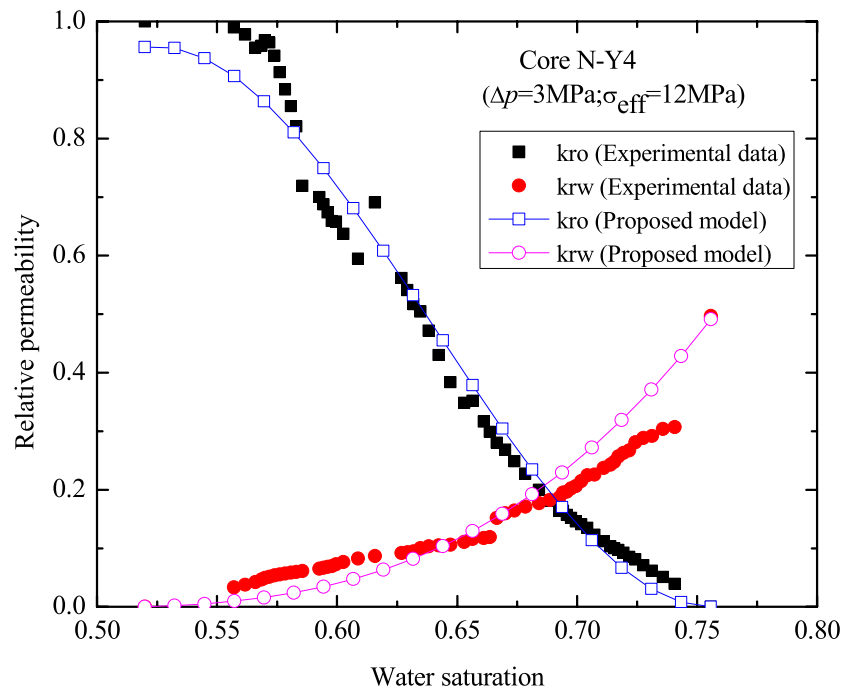

(b)

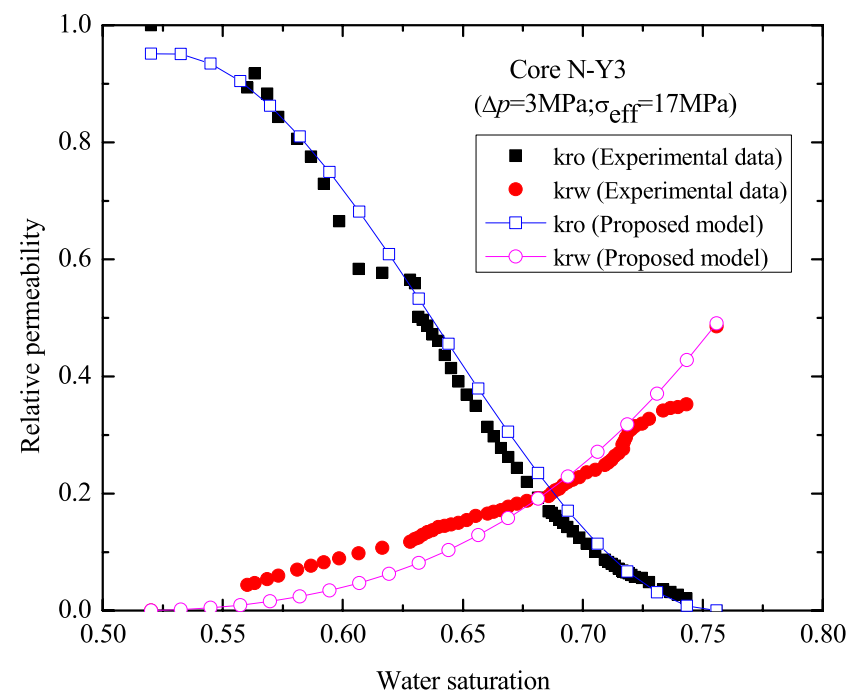

(c)

Fig. 7 Comparison between the experimental and predicted relative permeability curves for sample N-Y7, sample N-Y4 and sample N-Y3.

with the experimental data. Table 1 shows the physical parameters of the samples used in the experiments. The parameters applied in the proposed model should be similar to the corresponding sample. Taking the calculation of sample $\mathrm{N}-2 \mathrm{H}$ as example, the initial porosity $\varphi$ was $7.82 \%$, rock elastic modulus $E$ was $32.8 \mathrm{GPa}$, rock Poisson's ratio $v$ was 0.21 , the water phase viscosity was $0.676 \mathrm{mPa} \cdot \mathrm{s}$, oil phase viscosity was $2.662 \mathrm{mPa} \cdot \mathrm{s}$, the drawdown pressure and the effective stress were $5 \mathrm{MPa}$ and $20 \mathrm{MPa}$, respectively. In addition, the initial maximum radius $r_{\max }=0.92 \mu \mathrm{m}$ and the initial minimum radius $r_{\min }=0.001 \mu \mathrm{m}$ were applied in our model which could ensure the initial permeability of our simulated porous media is $K=2.49 \times 10^{-3} \mu \mathrm{m}^{2}$. The details about the parameters applied in the proposed model for each sample are summarized in Table 3. Figures 68 also illustrate that the predictions of our model exhibit similar variation trends as the experimental data, which verified the theoretical model.

Based on the experimental results, we find that the irreducible water saturation increases with effective stress and decreases with the drawdown pressure. Thus, the trend of the relative permeability versus the pressure condition should be investigated. Figure 9 demonstrates the irreducible water saturation versus pressure condition (the 


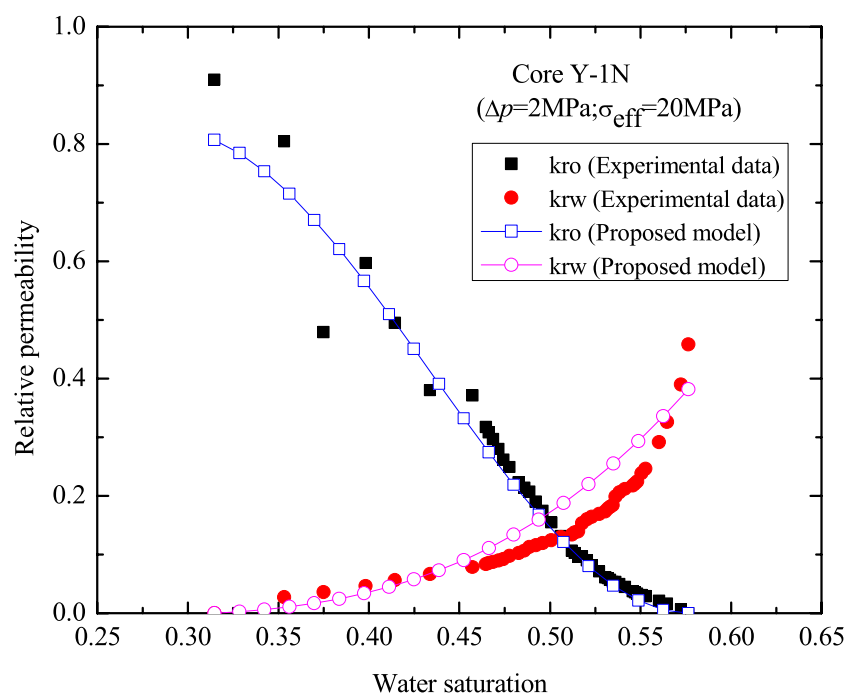

(a)

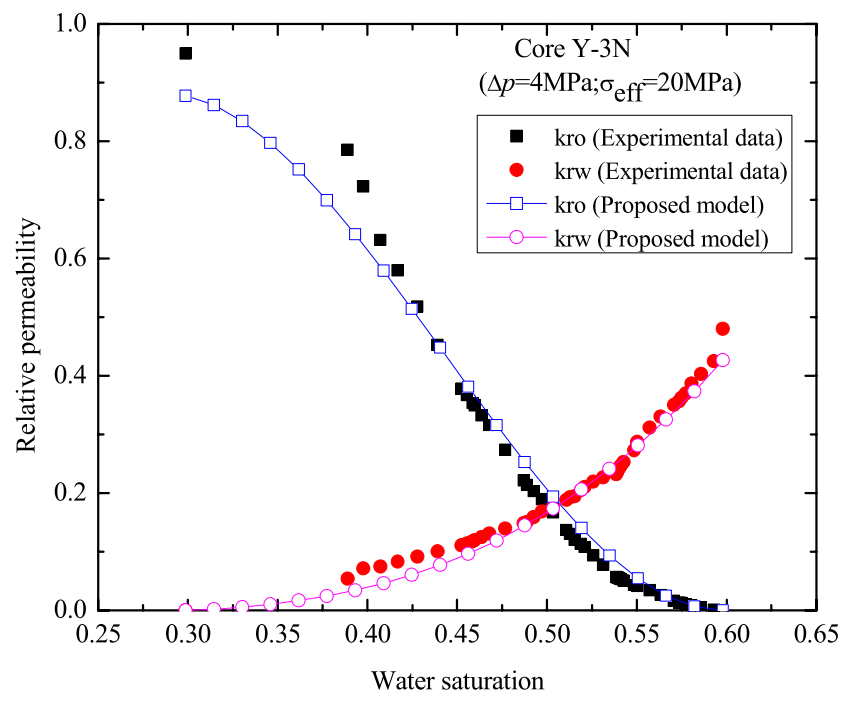

(c)

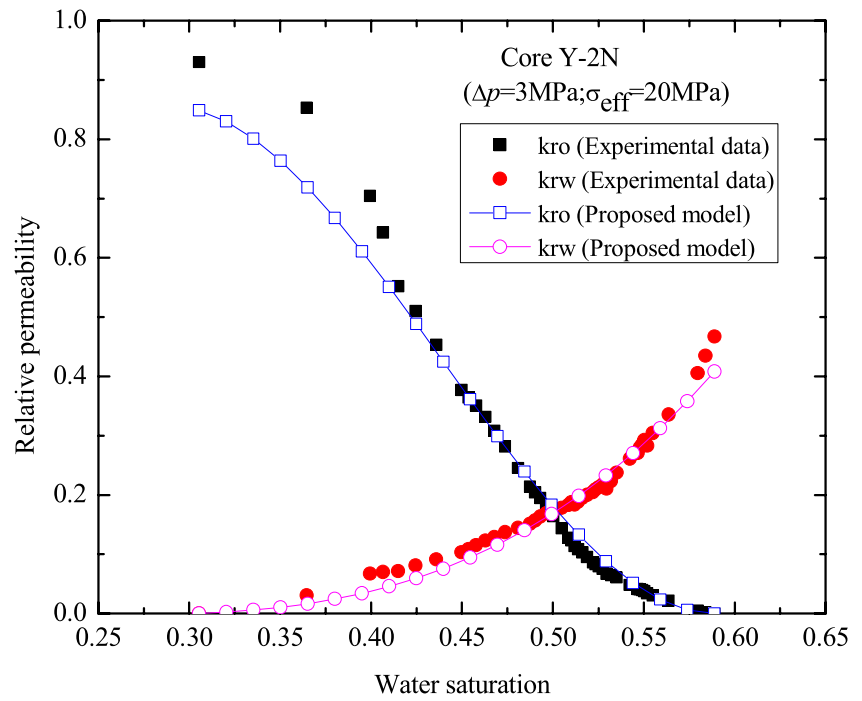

(b)

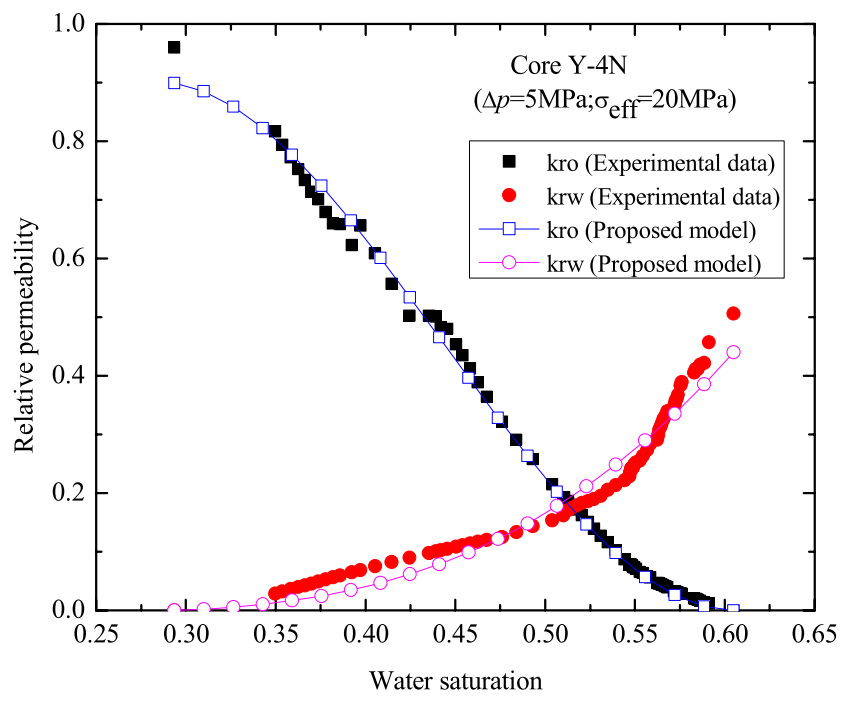

(d)

Fig. 8 Comparison between the experimental and predicted relative permeability curves for sample Y-1N, sample $\mathrm{Y}-2 \mathrm{~N}$, sample Y-3N and sample Y-4N.

Table 3 Parameters Applied in the Proposed Model.

\begin{tabular}{|c|c|c|c|c|c|c|c|c|c|}
\hline \multirow[t]{2}{*}{ Sample } & \multirow[t]{2}{*}{$\varphi(\%)$} & \multirow[t]{2}{*}{$r_{\max }(\mu \mathrm{m})$} & \multirow[t]{2}{*}{$r_{\min }\left(10^{-3} \mu \mathrm{m}\right)$} & \multirow[t]{2}{*}{$I$} & \multirow[t]{2}{*}{$E(\mathrm{GPa})$} & \multirow[t]{2}{*}{$v$} & \multicolumn{3}{|c|}{$\delta(\mu \mathrm{m})$} \\
\hline & & & & & & & $a$ & $b$ & $c$ \\
\hline $\mathrm{N}-2 \mathrm{H}$ & 7.82 & 0.92 & 1.00 & 0.091 & 32.8 & 0.21 & 1.001 & 0.261 & 0.596 \\
\hline $\mathrm{N}-3 \mathrm{H}$ & 8.01 & 0.92 & 1.00 & 0.114 & 32.8 & 0.21 & 1.001 & 0.261 & 0.548 \\
\hline N-Y7 & 15.86 & 1.02 & 1.02 & 0.361 & 12.6 & 0.25 & 0.561 & 0.261 & 0.509 \\
\hline N-Y3 & 14.88 & 1.01 & 1.01 & 0.361 & 12.6 & 0.25 & 0.561 & 0.261 & 0.509 \\
\hline N-Y4 & 15.66 & 1.01 & 1.01 & 0.368 & 12.6 & 0.25 & 0.561 & 0.261 & 0.509 \\
\hline $\mathrm{Y}-1 \mathrm{~N}$ & 11.57 & 1.69 & 1.69 & -0.148 & 25.5 & 0.24 & 0.338 & 0.261 & 0.109 \\
\hline $\mathrm{Y}-2 \mathrm{~N}$ & 11.35 & 1.68 & 1.68 & -0.148 & 25.5 & 0.24 & 0.338 & 0.261 & 0.109 \\
\hline $\mathrm{Y}-3 \mathrm{~N}$ & 11.26 & 1.69 & 1.69 & -0.148 & 25.5 & 0.24 & 0.338 & 0.261 & 0.109 \\
\hline $\mathrm{Y}-4 \mathrm{~N}$ & 11.14 & 1.70 & 1.70 & -0.148 & 25.5 & 0.24 & 0.338 & 0.261 & 0.109 \\
\hline
\end{tabular}




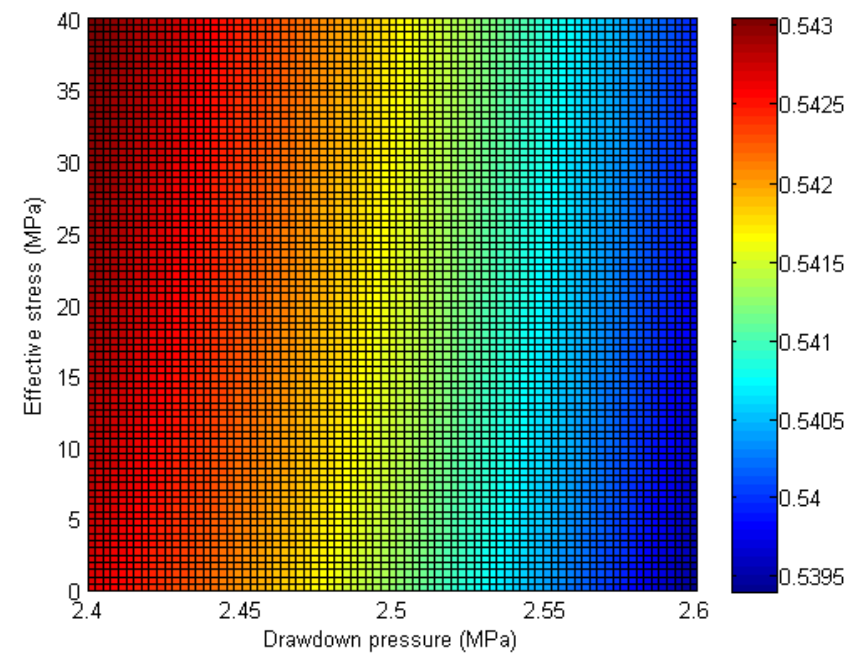

Fig. 9 Effect of the pressure condition on the irreducible water saturation.

effective stress and the drawdown pressure). In the calculation, the parameters are same with sample $\mathrm{N}-2 \mathrm{H}$. Figure 9 demonstrates that the increased irreducible water saturation corresponds to the increasing effective stress with a constant drawdown pressure. However, larger effective stress may decrease the irreducible water saturation for increasing drawdown pressure. For example, when the drawdown pressure is $2.4 \mathrm{MPa}$ and the effective stress is $5 \mathrm{MPa}$, the irreducible water saturation is $54.25 \%$. However, when the drawdown pressure is $2.6 \mathrm{MPa}$ and the effective stress is $40 \mathrm{MPa}$, the irreducible water saturation is only $54 \%$.

Figure 10 demonstrates the stress-dependent relative permeability versus water saturation at different rock wettability index $I$ when other parameters

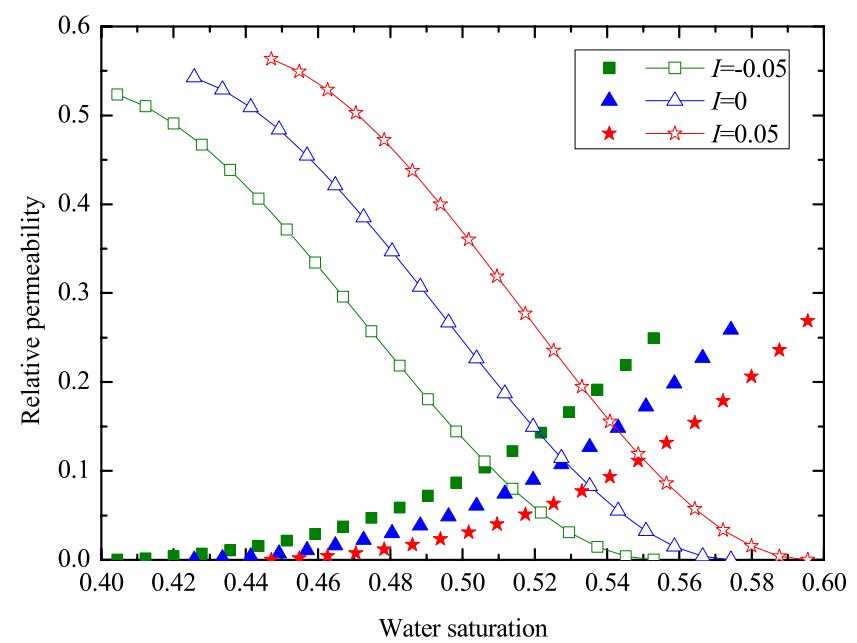

Fig. 10 Effect of the rock wettability index on the stressdependent relative permeability.

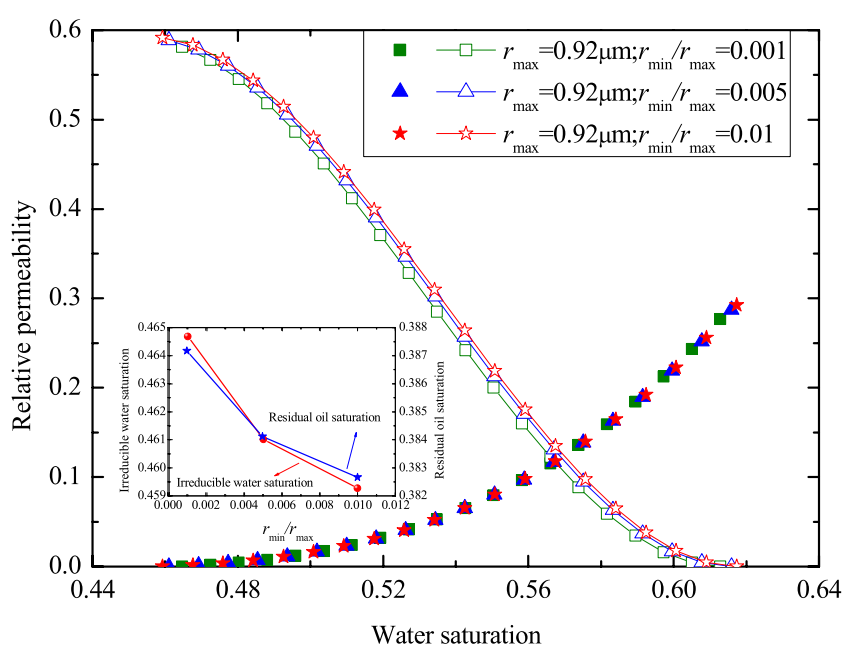

Fig. 11 Effect of the pore radius ratio on the stressdependent relative permeability.

are same with sample N-2H. Figure 10 shows that a higher oil phase relative permeability curve (or a lower water phase relative permeability curve) correspond to a larger rock wettability index $I$ at the same water saturation. And the irreducible water saturation increases as the rock wettability index $I$ increases, and the increasing rock wettability index $I$ lowers the residual oil saturation.

It has been shown that the structural parameters of the porous media have an important effect on the relative permeability ${ }^{44}$ Thus, the trend of the relative permeability versus the structural parameters of porous media, such as the pore radius ratio $r_{\min } / r_{\max }$, the pore fractal dimension $D_{f}$, and the tortuosity fractal dimension $D_{T}$, should be investigated. Figures 11113 show the significant effects of

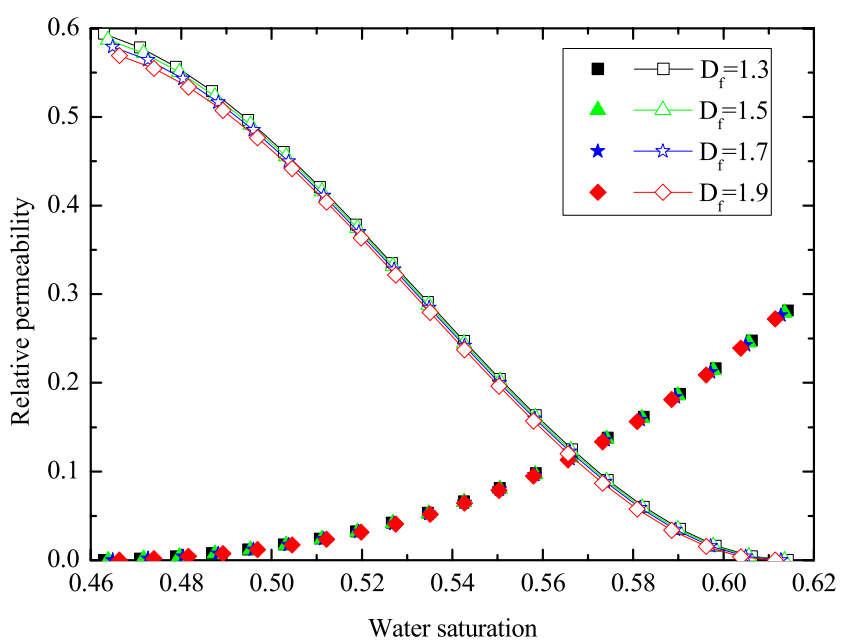

Fig. 12 Effect of the pore fractal dimension $D_{f}$ on the stress-dependent relative permeability. 


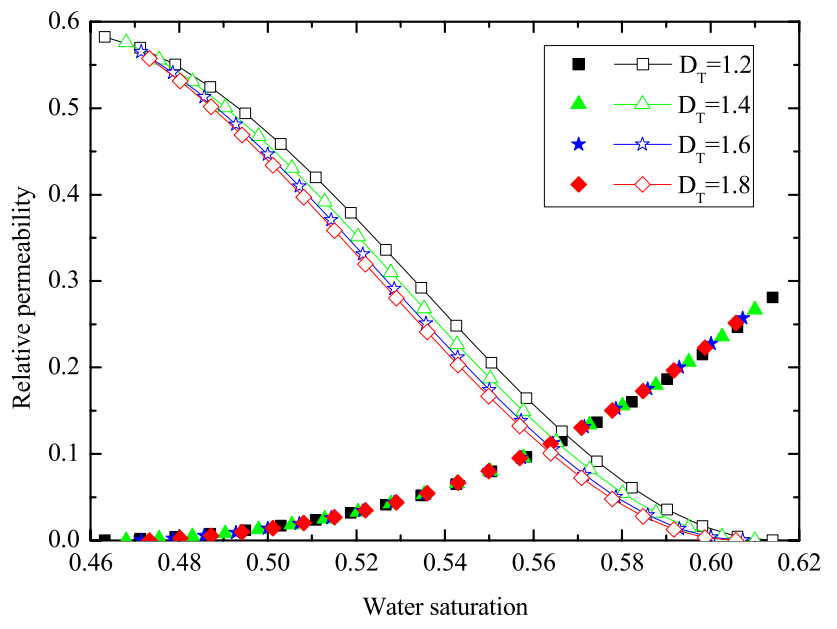

Fig. 13 Effect of the tortuosity fractal dimension $D_{T}$ on the stress-dependent relative permeability.

these parameters on the relative permeability curve for sample $\mathrm{N}-2 \mathrm{H}$.

Figure 11 shows the stress-dependent relative permeability versus water saturation at different pore radius ratio when other parameters are same with sample $\mathrm{N}-2 \mathrm{H}$. It is seen from Fig. 11 that a higher oil phase relative permeability curve corresponds to a larger pore radius ratio $r_{\min } / r_{\max }$ at the same water saturation, and both irreducible water saturation and residual oil saturation decrease as the pore radius ratio $r_{\min } / r_{\max }$ increases.

Figures 12 and 13 illustrate the effect of the pore fractal dimension $D_{f}$ and tortuosity fractal dimension $D_{T}$ on the stress-dependent relative permeability. It is concluded from Fig. 12 that smaller oil phase relative permeability curves correspond to larger pore fractal dimensions with specific water saturation and the irreducible water saturation and residual oil saturation increase as the pore fractal dimension increases. Figure 13 shows a significant decrease in the oil phase relative permeability as the tortuosity fractal dimension increases and the greater tortuosity fractal dimension is, the larger irreducible water saturation (or residual oil saturation) will be. Figures 12 and 13 also show that the effect of pore fractal dimension or the tortuosity fractal dimension on water phase relative permeability is not significant. The main reason for this is that the increased fractal dimension implies increases of percent of small pores and the increased tortuosity fractal dimension implies the increase of flow resistance in porous media. The increased fractal dimension or the increased tortuosity fractal dimension can reduce the flow velocity for each single phase in porous media. As water phase is the wetting fluid for the sample $\mathrm{N}-2 \mathrm{H}$, water phase flow occurs close to capillary surface, and oil phase flow occurs in the center of the capillary. Flow velocity of water phase drops much slower than that of oil phase with the increased pore fractal dimension (or the increased tortuosity fractal dimension) So the effect of pore fractal dimension or tortuosity fractal dimension on water phase relative permeability is not significant.

It has been shown that the relative permeability curve should be a function of saturation and viscosity 43 Therefore, the trend of relative permeability versus fluid viscosity is of theoretical significance. Figure 14 shows the significant influences of fluid viscosity ratio on the relative permeability. As the oil phase viscosity $\mu_{\mathrm{o}}=2.662 \mathrm{mPa} \cdot \mathrm{s}$ is given, a larger fluid viscosity ratio corresponds to a smaller water phase viscosity value. It is seen from Fig. 14 that a greater oil phase relative permeability corresponds to a larger fluid viscosity ratio value, and the irreducible water saturation and residual oil saturation increase as the fluid viscosity ratio increases. The result can be explained as: for the sample $\mathrm{N}-2 \mathrm{H}$, water phase is the wetting fluid. During the twophase flow, water phase flow occurs close to capillary surface, the flow of the adjacent oil phase passing by it, to some extent, can be considered as a sliding motion in which the water phase provides lubrication. So a greater oil phase relative permeability corresponds to a larger fluid viscosity ratio value. Figure 14 also illustrates that the effect of fluid viscosity ratio on water phase relative permeability is not significant which can also be seen from Eq. (7).

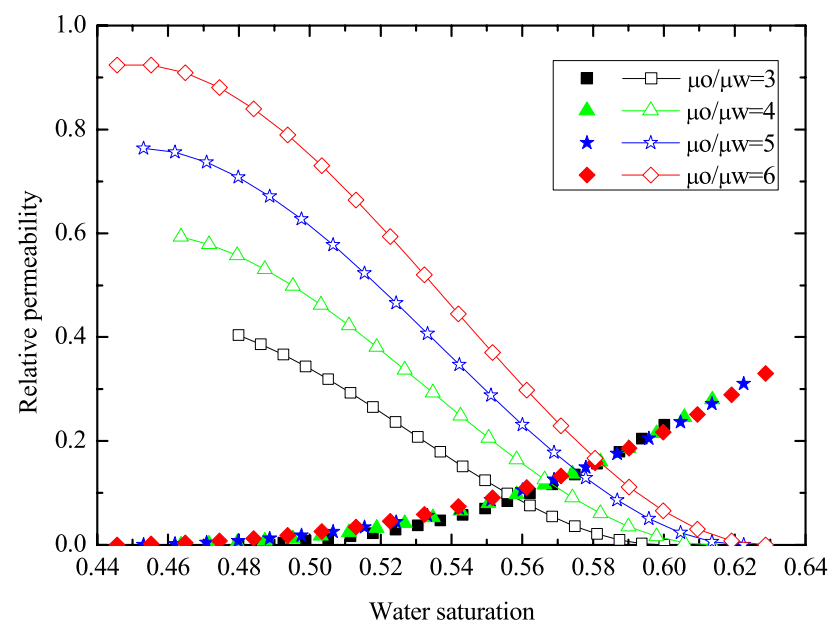

Fig. 14 Effect of the viscosity ratio on the stress-dependent relative permeability. 


\section{CONCLUSIONS}

In this paper, laboratory tests have been conducted to study the effect of pressure condition (drawdown pressure and effective stress) on stress-dependency of relative permeability curves. And a corresponding fractal model for the stress-dependent relative permeability was derived to interpret the experimental results. The predictions from the proposed analytical model exhibited similar variation trends as the experimental data, which verified the validity of the theoretical model to predict the stressdependent relative permeability under different pressure conditions. With the theoretical and experimental study of the stress-dependent relative permeability in this paper, following conclusions can be drawn:

(1) The stress-dependent relative permeability is the function of effective stress, rock wetting index, fluid viscosity ratio, structural parameters of porous media, as well as the drawdown pressure.

(2) Under the condition of constant drawdown pressure, a greater irreducible water saturation corresponds to a larger effective stress value. However, larger effective stress may decrease the irreducible water saturation for greater drawdown pressure.

(3) The parametric study shows that the oil phase relative permeability decreases with the increasing pore fractal dimension and tortuosity fractal dimension, and increases with increasing pore radius ratio and fluid viscosity ratio. However, the effects of these parameters on the water phase relative permeability are not significant. A greater oil phase relative permeability curve (or a smaller water phase relative permeability curve) corresponds to a larger rock wettability index value.

(4) The proposed model for stress-dependent relative permeability can reveal more mechanisms that affect the coupled flow deformation behavior in porous media. And the proposed model might have potential applications in the development of tight unconventional reservoirs. However, it should be noted that oil phase flow is not coupled with the water phase flow in the model. Multi-phase fluid flow in a porous medium under effective stress is an interesting and challenging topic, and additional work is still required.

\section{ACKNOWLEDGMENTS}

The authors are grateful for financial support from the State Major Science and Technology Special Project of China during the 13th Five-Year Plan (2016ZX05014-004) and China Postdoctoral Science Foundation (2017M610706).

\section{REFERENCES}

1. H. Zhang et al., Solute transport in nearly saturated porous media under landfill clay liners: A finite deformation approach, J. Hydrol. 479(2) (2013) 189-199.

2. S. Wang and K. C. Hsu, The application of the firstorder second-moment method to analyze poroelastic problems in heterogeneous porous media, J. Hydrol. 369(1) (2009) 209-221.

3. A. Gajo, B. Loret and T. Hueckel, Electro-chemomechanical couplings in saturated porous media: Elastic-plastic behaviour of heteroionic expansive clays, Int. J. Sol. Struct. 39(16) (2002) 43274362.

4. L. B. Neto, A. Kotousov and P. Bedrikovetsky, Elastic properties of porous media in the vicinity of the percolation limit, J. Petrol. Sci. Eng. 78(2) (2011) 328-333.

5. N. Mokni et al., Deformation induced by dissolution of salts in porous media, Phy. Chem. Earth A/B/C 3(2) (2008) S436-S443.

6. A. F. Gangi, Variation of whole and fractured porous rock permeability with confining pressure, Int. J. Rock Mech. Min. Sci. Geomech. Abstracts 15(5) (1978) 249-257.

7. C. R. McKee, A. C. Bumb and R. A. Koenig, Stressdependent permeability and porosity of coal and other geologic formations, SPE Form. Eval. 3(1) (1988) 81-91.

8. P. D. McKinney, J. A. Rushing and L. A. Sanders, Applied reservoir characterization for maximizing reserve growth and profitability in tight gas sands: A paradigm shift in development strategies for lowpermeability gas reservoirs, in SPE Gas Technology Symp. (Society of Petroleum Engineers, 2002), pp. $1-12$.

9. R. A. Archer, Impact of stress sensitive permeability on production data analysis, in SPE Unconventional Reservoirs Conf. (Society of Petroleum Engineers, 2008), pp. 1-9.

10. S. Zhu, Experiment research of tight sandstone gas reservoir stress sensitivity based on the capillary bundle model, in SPE Annual Technical Conf. Exhibition (Society of Petroleum Engineers, 2013), pp. 112.

11. X. Tan et al., Fractal analysis of stress sensitivity of permeability in porous media, Fractals 23(2) (2015) 1550001. 
12. X. Tan et al., Study of the effects of stress sensitivity on the permeability and porosity of fractal porous media, Phys. Lett. A 379(39) (2015) 2458-2465.

13. H. Zhang et al., A novel quantitative petrophysical model for the stress sensitivity of tight sandstones, J. Petrol. Sci. Eng. 122(5) (2014) 657-666.

14. G. Lei et al., A fractal model for the stressdependent permeability and relative permeability in tight sandstones, J. Canad. Petrol. Technol. 54(1) (2015) 36-48.

15. J. W. Wilson, Determination of relative permeability under simulated reservoir conditions, AIChE J. 2(1) (1956) 94-100.

16. H. S. Ali et al., The effect of overburden pressure on relative permeability, in Middle East Oil Show (Society of Petroleum Engineers, 1987), pp. 1-6.

17. C. Jones et al., Stress sensitivity of saturation and end-point relative permeabilities, in Int. Symp. Society of Core Analysts (Society of Petroleum Engineers, 2001), pp. 1-12.

18. A. Al-Quraishi and M. Khairy, Pore pressure versus confining pressure and their effect on oil-water relative permeability curves, J. Petrol. Sci. Eng. 48(1) (2005) 120-126.

19. H. A. Khan, Shear Induced Relative Permeability Change in Uncemented Sands (The University of Texas at Austin, Austin, Texas, 2009).

20. M. Hamoud, R. J. Chalaturnyk and J. Leung, Influence of geomechanical processes on relative permeability, in The 21st Canadian Rock Mechanics Sympos. (Society of Petroleum Engineers, 2012), pp. 1-9.

21. L. J. Pyrak-Nolte, N. G. Cook and L. R. Myer, Stratified percolation model for saturated and unsaturated flow through natural fracture, in The 1st Annual Int. High-Level Radioactive Waste Management Conf., Vol. 1 (American Nuclear Society, 1990), pp. 551-558.

22. A. E. McDonald et al., Some important considerations in the simulation of naturally fractured reservoirs, in Low Permeability Reservoirs Symp. Conf. (Society of Petroleum Engineers, 1991), pp. 117-124.

23. P. Q. Lian, L. S. Cheng and C. Y. Ma, The characteristics of relative permeability curves in naturally fractured carbonate reservoirs, J. Canad. Petrol. Technol. 51(2) (2012) 137-142.

24. X. Zheng et al., Gas/water flowing ability influence experimental study of permeability stress sensibility in tight gas reservoir, Well Logging Technol. 4(2) (2013) 360-363.

25. D. Huo and S. M. Benson, Experimental investigation of stress-dependency of relative permeability in rock fractures, Transp. Porous Media 113(3) (2016) $567-590$.

26. J. Toth et al., Convenient formulae for determination of relative permeability from unsteady-state fluid displacements in core plugs, J. Petrol. Sci. Eng. 36(1) (2002) 33-44.

27. E. F. Johnson, D. P. Bossler and V. O. Naumann, Calculation of relative permeability from displacement experiments, Pet. Trans. AIME 216 (1959) $370-372$.

28. J. Xu et al., Study on relative permeability characteristics affected by displacement pressure gradient: Experimental study and numerical simulation, Fuel 163 (2016) 314-323.

29. A. J. Katz and A. H. Thompson, Fractal sandstone pores: Implications for conductivity and pore formation, Phys. Rev. Lett. 54(12) (1985) 1325-1328.

30. M. Yun et al., Fractal analysis of power-law fluid in a single capillary, Chin. Phys. Lett. 25(2) (2008) 616-619.

31. J. P. Hansen and A. T. Skjeltorp, Fractal pore space and rock permeability implications, Phys. Rev. B 38(4) (1988) 2635-2638.

32. B. Xiao et al., Research on relative permeability of nanofibers with capillary pressure effect by means of fractal-monte Carlo technique, J. Nanosci. Nanotechnol. 17(9) (2017) 6811-6817.

33. J. Cai et al., Generalized modeling of spontaneous imbibition based on Hagen-Poiseuille flow in tortuous capillaries with variably shaped apertures, Langmuir 30(18) (2014) 5142-5151.

34. W. Wei and Y. Xia, Geometrical, fractal and hydraulic properties of fractured reservoir: A minireview, Adv. Geo-Energ. Res. 1(1) (2017) 31-38.

35. W. Wei et al., An electrical conductivity model for fractal porous media, Geophys. Research Lett. 42(12) (2015) 4833-4840.

36. P. Xu et al., Prediction of relative permeability in unsaturated porous media with a fractal approach, Int. J. Heat Mass Transf. 64(3) (2013) 829-837.

37. Q. Zheng et al., A fractal model for gas slippage factor in porous media in the slip flow regime, Chem. Eng. Sci. 87(3) (2013) 209-215.

38. S. Mo et al., Effect of the drawdown pressure on the relative permeability in tight gas: A theoretical and experimental study, J. Nat. Gas Sci. Eng. 24 (2015) 264-271.

39. J. Cai et al., Recent advances on fractal modeling of permeability for fibrous porous media, Fractals 23(1) (2015) 1540006.

40. G. Lei et al., Study of stress-sensitivity of lowpermeability reservoir based on arrangement of particles, Rock Soil Mech. 35(S1) (2014) 209-214.

41. A. F. Gangi, Hertz theory applied to the porositypressure, permeability-pressure and failure strengthporosity variations of porous rocks, in The 17th US Symp. Rock Mechanics (USRMS) (American Rock Mechanics Association, 1976), pp. 1-8.

42. X. Tian et al., An improved solution to estimate relative permeability in tight oil reservoirs, 
J. Petrol. Explor. Product. Technol. 5(3) (2014) 305-314.

43. G. Lei et al., A novel fractal model for two-phase relative permeability in porous media, Fractals 23(2) (2015) 1550017.

44. P. M. Adler, Transports in fractal porous media, J. Hydrol. 187(1) (1996) 195-213.

45. B. Yu and J. Li, Some fractal characters of porous media, Fractals 9(3) (2001) 365-372.

46. B. Yu and W. Liu, Fractal analysis of permeabilities for porous media, AIChE J. 50(1) (2004) 46-57.

\section{APPENDIX A. FRACTAL \\ THEORY \\ CONSIDERING \\ STRESS \\ SENSITIVITY}

According to the fractal approach, the probability density function for pore size distribution in fractal porous media can be obtained as $39[45$

$$
f\left(r_{0}\right)=D_{f 0} r_{\min 0}^{D_{f 0}} r_{0}^{-\left(D_{f 0}+1\right)},
$$

when the effect of stress sensitivity is considered, Eq. (A.1) can be rewritten as

$$
f(r)=D_{f} r_{\min }^{D_{f}} r^{-\left(D_{f}+1\right)} .
$$

Assume the total number of pores in the porous media keeps in constant during the process of deformation, the following equation can be written as 14 .

$$
N=\left(\frac{r_{\max }}{r_{\min }}\right)^{D_{f}}=\left(\frac{r_{\max 0}}{r_{\min 0}}\right)^{D_{f 0}},
$$

where $N$ is the number of pores of a unit cell, $r_{\max 0}$ and $r_{\min 0}$ are the maximum and minimum pore radius of porous media at zero stress, respectively. $D_{f 0}$ is fractal dimension of pore before deformation. $r_{\max }$ and $r_{\min }$ are the stress-dependent maximum and the stress-dependent minimum pore radius of porous media after deforming, respectively. $D_{f}$ is stress-dependent fractal dimension, which can be rewritten as 45

$$
\begin{aligned}
D_{f} & =D_{f 0} \frac{\ln \left(r_{\max 0} / r_{\min 0}\right)}{\ln \left(r_{\max } / r_{\min }\right)} \\
& =\left[2-\frac{\ln \varphi_{0}}{\ln \left(r_{\min 0} / r_{\max 0}\right)}\right] \frac{\ln \left(r_{\max 0} / r_{\min 0}\right)}{\ln \left(r_{\max } / r_{\min }\right)},
\end{aligned}
$$

in which $\varphi_{0}$ is the porosity of the porous media at zero stress.

The relationship between the capillary length and capillary size also exhibits the self-similar fractal scaling law, $\stackrel{39146}{ }$ and when the effect of stress sensitivity is considered, the capillary length under stress can be rewritten as

$$
L_{\tau}=(2 r)^{1-D_{T}} L^{D_{T}},
$$

where $L_{\tau}$ is the length of the tortuous capillary under stress and $D_{T}$ is the stress-dependent tortuosity fractal dimension which can also be calculated by 45146

$$
D_{T}=1+\frac{\ln \bar{\tau}}{\ln \left[L_{\tau} /(2 \bar{r})\right]}
$$

in which

$$
\begin{aligned}
& \frac{L_{\tau}}{2 \bar{r}}=\frac{D_{f}-1}{\sqrt{D_{f}}} \sqrt{\frac{1-\varphi}{4 \varphi} \frac{\pi}{2-D_{f}}}\left(\frac{r_{\max }}{r_{\min }}\right)^{\frac{D_{f 0}}{D_{f}}}, \\
& \bar{\tau}=\frac{1}{2}\left[\begin{array}{c}
1+\frac{1}{2} \sqrt{1-\left(r_{\min } / r_{\max }\right)^{2-D_{f}}} \\
+\frac{\sqrt{\begin{array}{l}
{\left[1-\sqrt{\left.1-\left(r_{\min } / r_{\max }\right)^{2-D_{f}}\right]^{2}}\right.} \\
+\frac{1}{4}\left[1-\left(r_{\min } / r_{\max }\right)^{2-D_{f}}\right]
\end{array}}}{1-\sqrt{1-\left(r_{\min } / r_{\max }\right)^{2-D_{f}}}}
\end{array} .\right.
\end{aligned}
$$

